\title{
DIY heritage institutions as third places: caring, community and well-being among volunteers at the Australian Jazz Museum
}

\author{
Zelmarie Cantillon and Sarah Baker
}

\section{Introduction}

Community-based, do-it-yourself (DIY) archives and museums of popular music are cultural institutions that also serve important social and affective functions. In this article, we aim to consider the extent to which such institutions can be conceptualised as "third places" (Oldenburg, 1999) for their volunteers. Using the Australian Jazz Museum (AJM) as a case study, we explore its parallels with, and departures from, Oldenburg's indicators of third place. Our discussion is organised thematically, based on the characteristics of third place that are most relevant to the AJM and to our interview data: namely, how it promotes sociality, nurtures friendships, creates environments for caring and living, and enables productive retirement (see Oldenburg 1996/7, 1999 for full lists of indicators). We suggest that these characteristics contribute to a distinctive social world (Stebbins, 1982), create a sense of community (McMillan \& Chavis, 1986) and support the well-being of volunteers.

The AJM, formerly the Victorian Jazz Archive, was established in 1996 by a community of enthusiasts, a number of whom are still alive and remain connected to the institution, who recognised the need for a state-based repository which could house jazz ephemera that would otherwise be in danger of vanishing from the public record (see Baker \& Huber, 2012; Sutton, 2015). The AJM is among a growing number of what Baker and Huber (2013) call DIY heritage institutions, a subset of community archives and museums which focus on the preservation of cultural artefacts and which are almost exclusively founded by enthusiasts and run by volunteers. Community archives and museums are a grassroots heritage practice characterised by "the active participation of a community 
documenting and making accessible the history of their particular group and/or locality on their own terms" (Flinn, Stevens, \& Shepherd, 2009, p. 73, original emphasis).

In many DIY heritage institutions, including the AJM, the volunteers are retirees or close to retirement age (see Baker \& Huber, 2012). Older adults are more likely than younger people to volunteer in these institutions for a number of reasons, including having more time available to commit to unpaid work, being more interested in "leaving a legacy" (MorrowHowell, 2010, p. 462), and, as will be discussed throughout this article, wanting to engage in productive tasks and form social bonds post-retirement. Volunteering at a DIY heritage institution can be a form of "serious leisure" (Stebbins, 1982, 1996), offering meaningful work following the cessation of formal paid employment. The positive effects of volunteering on the well-being of older adults have been well documented in scholarly literature. Reported benefits associated with volunteering include improvements to mental and physical health (Musick, Herzog, \& House, 1999; Schwingel, Niti, Tang, \& Ng, 2009; Tang, Choi, \& Morrow-Howell, 2010; Thoits \& Hewitt, 2001) and higher levels of life satisfaction and happiness (Schwingel et al., 2009; Thoits \& Hewitt, 2001; Van Willigen, 2000). Pilkington, Windsor and Crisp (2012) suggested that these benefits are derived from the increased social support that volunteering experiences offer, while Greenfield and Marks (2004) posited that volunteering mitigates some of the negative effects of role-identity changes that come with ageing, such as shifts in employment, parental and partner identities implicated in retirement, divorce and death. In this article, we seek to examine how such benefits manifest in the specific context of a community heritage institution. Although there is a handful of literature on the experience of volunteers in heritage institutions (e.g. Edwards \& Graham, 2006; Graham, 2004; Holmes, 2003; Orr, 2006; Stamer, Lerdall, \& Guo, 2008; Yang, 2015), these examinations have predominantly focused on the mainstream sector (comprised of state- 
funded museums, galleries and archives, which employ paid staff in addition to recruiting volunteers). In contrast, we focus on an institution founded and run completely by volunteers.

\section{Literature Review}

\section{Third Places}

Oldenburg $(1996 / 7,1999)$ argued that everyday life has become increasingly characterised by a "two-stop model" (1999, p. 9) in which one's interactions are largely restricted to home (first place) and work (second place). This is particularly the case for those living in suburbia, with lengthy commutes to and from work leaving little time for leisure and socialising, and with the suburban landscape being designed to emphasise privacy and isolation over community and connection (Oldenburg, 1999; Oldenburg \& Brissett, 1982). As a consequence, Oldenburg posits that there has been a decline in informal gathering places where people can meet up and "hang out" - what he calls third places. Putnam (2000) echoed these sentiments, arguing that interactive community spaces - those which function to build and maintain social capital - have been disappearing for decades.

Whether or not this trend is actually occurring is debatable. The counterargument is that spaces for informal sociality and community are changing rather than disappearing. For example, the rise of digital technologies allows for different means through which people can make communities, interact, feel a sense of belonging and build social capital (Ducheneaut et al., 2007; Moore et al., 2009; Yuen \& Johnson, 2017). This is especially important for those who are geographically isolated and/or housebound due to physical disabilities, illness, carer responsibilities, etc., and may not otherwise be able to regularly engage in physical third places. Nonetheless, third places serve vital social functions. In particular, Oldenburg $(1996 / 7,1999)$ suggested that third places provide temporary relief from the often highly predictable and restrictive sociality characteristic of home and work, which usually involve 
set routines, roles and responsibilities. In contrast, Oldenburg (1999) asserted that the social relations of third places tend to be less hierarchical and inhibited, offering possibilities for the expression of pure sociability in Simmel's (1949) terms - "association for its own sake" (p. 254), with pleasure derived simply from being in the presence of others and talking to them. Oldenburg (1996/7, 1999; Oldenburg \& Brissett, 1982) outlined various characteristics that could be taken to define a third place. There is considerable overlap in these indicators, with each of Oldenburg's lists referring to conversation, neutral ground, a playful atmosphere, accessibility and accommodation. A number of benefits underpin these characteristics. Oldenburg (1999) suggested that third places offer a sense of novelty and unpredictability in that they typically feature diverse, shifting groups of people participating at different times. They constitute their own social worlds (Stebbins, 1982) in which one can playfully interact with different kinds of people, making friends with other regulars and building social capital in a relaxed, positive atmosphere (Fisher, Saxton, Edwards, \& Mai, 2007; Harris, 2007; Oldenburg, 1999). As such, on an individual level, engagement with third places can have positive effects on well-being by providing support networks and raising the spirits of participants, warding off stress, loneliness and isolation (Oldenburg, 1999; Rosenbaum, 2006). Below, we explore the benefits of engaging in the AJM in terms of how it enhances well-being and creates a sense of community for volunteers. For the purposes of this article, we define a "sense of community" in the AJM based on elements outlined by McMillan and Chavis (1986): feelings of belonging or membership to the group; a collective sense of mattering to the institution and to other volunteers; the capacity for the institution to meet some of the needs of its members; and shared affective experiences based on participation in the same space and in similar activities.

Oldenburg's examples of third places, or "great good places," vary widely, taking in Parisian sidewalk cafes, English pubs, Japanese teahouses and American saloons, to local 
bars, coffee shops and main streets. However, not all of these types of sites are third places in that they may be lacking the most fundamental characteristics of such places - specifically, they may not feature or be conducive to the kind of voluntary, informal sociality that creates a sense of community among regulars. Even a site that functions as a third place for one person may not for another. As such, the particular goods, services or leisure activities third places provide are somewhat inconsequential, apart from the fact that some common factors - such as availability of food and drink - typically encourage informal sociality (Mehta \& Bosson, 2010). Indeed, many different sites can function as third places provided they have some of the qualities and produce some of the affects/effects listed above (Purnell, 2015).

Scholarly literature drawing on Oldenburg's concept of third place has applied, adapted and extended his ideas in relation to a variety of sites, including physical spaces such as university campuses (Banning, Clemons, McKelfresh, \& Gibbs, 2010), fast food restaurants (Cheang, 2002) and leisure spaces (Hindley, 2018; Mair, 2009), as well as online spaces (e.g. Ducheneaut, Moore, \& Nickell, 2007; McArthur \& White, 2016; Moore, Hankinson Gathman, \& Ducheneaut, 2009). A handful of this literature specifically discusses the role that third places can play in improving the lives of older adults (Campbell, 2014; Cheang, 2002; Rosenbaum et al., 2009; Rosenbaum, Ward, Walker, \& Ostrom, 2007). In terms of the galleries, libraries, archives and museums (GLAM) sector, there has been one article published on an art gallery as a third place (Slater \& Koo, 2010), and multiple other studies which consider libraries as potential third places (e.g. Aabø \& Audunson, 2012; Fisher et al., 2007; Harris, 2007; Lin, Pang, \& Luyt, 2015). However, there is no literature that analyses archives, museums or other heritage institutions as third places. Yet DIY heritage institutions are particularly worthy of analysis because they are community-based initiatives that rely on nonobligatory association (volunteer labour) motivated by particular 
rewards (which have significant overlap with the benefits related to third places), and are especially conducive to expressions of serious leisure.

Oldenburg's third place indicators have been found to be more or less present in various sites. In some cases, the literature deduced that without meeting all of Oldenburg's indicators, their sites of focus could not necessarily be considered third places (e.g. Aabø \& Audunson, 2012; Fisher et al., 2007; Lin et al., 2015). Other work, however, argued that some spaces can function as third places despite subtle differences from Oldenburg's components. In this article, we make a similar argument, highlighting the ways in which the AJM shares similarities with, but also differs from, Oldenburg's understanding of third place. As with other studies, we use these points of difference to rethink some of the assumptions underlying Oldenburg's work. For instance, Yuen and Johnson (2017) and Freeman (2008) noted it is problematic to assume any space, let alone a third place, can be truly nonhierarchical, equal and inclusive. In commercial spaces that Oldenburg himself identifies as third places, such as coffee shops and pubs, there are hierarchies present in terms of staff being required to play host and fulfil certain customer services roles (Moore et al., 2009). Thus, a third place for customers may still function as a traditional first place for its workers. Moreover, such sites can be considered somewhat exclusionary in the sense that patrons require a degree of economic capital and physical mobility in order to access and socialise within them (Glover \& Parry, 2009). Likewise, heritage institutions cannot be completely egalitarian in that (among other reasons, as described below) they require a certain amount of economic and cultural capital to access and meaningfully engage with them.

In his study on social gatherings in residential properties, Purnell (2015) problematised Oldenburg's notion that third places exist outside of the spaces of home and work, and instead argued that what makes a third place is more about "use of space as opposed to descriptions of place" (p. 60, original emphasis). In our article, we similarly 
depart from Oldenburg's work in that we observe the ways in which a workplace in the community heritage sector - the Australian Jazz Museum - functions as a third place for its volunteers. We suggest that, in such a context, the distinctions between the social and affective qualities associated with "home," "work" and "leisure" become blurred, particularly with so many of its volunteers being engaged in what Stebbins $(1982,1996)$ calls "serious leisure."

\section{Casual and Serious Leisure}

Long-term heritage volunteers can be understood as distinct from paid staff as well as from visitors partaking in casual leisure (Orr, 2006; Stamer et al., 2008; Yang, 2015). Stebbins (1997) broadly defined casual leisure as "immediately, intrinsically rewarding, relatively short-lived pleasurable activity requiring little or no special training to enjoy it” (p. 18). By contrast, he observed that serious leisure, such as volunteering, involves "the acquisition and expression of a combination of special skills, knowledge, and experience" (Stebbins, 1996, p. 211). It entails obligations to be in specific places at particular times, performing designated tasks, but without the remuneration typical of formal employment (Stebbins, 1982, 1996). Such volunteers are usually hobbyists or enthusiasts, with their commitment and dedication derived from their passion (Orr, 2006; Stebbins, 1982, 1996). Although motivated, in part, by altruism, volunteers also become deeply invested in these activities for the personal rewards or "durable benefits" (Stebbins, 1982, p. 257) they yield, including opportunities for socialising, having fun, learning new skills, self-actualisation, and creating a sense of belonging (Stamer et al., 2008; Stebbins, 1982, 1996). In this way, serious leisure contributes to both individual and community well-being (Stebbins, 1982). Of course, not all volunteers in the AJM are engaging in serious leisure. For new volunteers who may not have archival skills or jazz-related interests or hobbies, their leisure is more casual at first. However, their activities are distinct from the casual leisure of visitors in that they are involved in the 
production of the museum rather than only its consumption (Orr, 2006); they must commit to working certain hours and performing required tasks during that time; and their leisure inevitably becomes more "serious" with ongoing participation (as described below).

Stebbins (1982) observed that participation in sites of serious leisure can create subcultures or social worlds with particular norms, routines, practices and other qualities (see also Stamer et al., 2008). As we explore below, the AJM constitutes one such social world specifically, a third place - arising from a community of practice, and with a distinct atmosphere and sociality. It is these social and affective aspects of space - rather than physical or material qualities - that are the focus of this article.

\section{Methodology}

\section{Background}

This article draws on data from two Australian Research Council (ARC) funded projects focused on popular music heritage practices which were conducted between 2010-2012 (Project 1) and 2013-2015 (Project 2) respectively. Project 1 was concerned with how popular music's past appears in cultural memory and public culture, from television documentaries and popular writing, through to museums and archives, as well as in the more small-scale, personal memories of individuals. Based on findings from Project 1, which included a study of six volunteer-managed archives and museums (see Baker, 2017), Project 2 sought to consider the emergence of community archives and related DIY heritage institutions as developing specialised repositories for popular music's material culture, and the important work of volunteers in these places. Over the course of these qualitative research projects, 125 semi-structured ethnographic interviews were conducted with founders, volunteers and other heritage workers in 23 DIY archives, museums and halls of fame in 10 countries: Australia, Austria, Czech Republic, Germany, Iceland, Netherlands, New Zealand, 
Switzerland, United Kingdom and United States. The interview schedule included questions about the founding of the DIY heritage institution, the practices and processes of collection, preservation and display, and the challenges and pleasures of volunteering in these places.

For the purposes of this article, we adopt a case study approach (Feagin, Orum, \& Sjoberg, 1991) to offer an in-depth analysis of issues reflected in the much larger comparative data set (see Baker, 2017), but which were most strongly expressed in the data collected at the AJM. Case-oriented theory testing can be valuable for the revision and refinement of existing theoretical and conceptual frameworks due to it being "unusual for an empirical case to conform well to any given theory" (Ragin \& Schneider, 2014, p. 150). The social and affective dimensions of the AJM were pronounced in the data due to the level of access the researchers had to the AJM and its volunteers. Fieldwork for the majority of research sites comprised single visits. The AJM, however, participated in both projects, with interviews conducted at the organisation on three days during Project 1 (31 May 2011, 19 July 2011 and 26 June 2012) and two days during Project 2 (18 September 2015 and 30 November 2015). Further, a two-week period of participant observation was undertaken at the AJM in October 2013. This extended time provided opportunities for the researcher to work alongside volunteers - for example, assisting with duties attached to tour group activities held at the archive, and to observe and engage with volunteers during events the AJM held for the Victorian Seniors Festival. Unstructured and semi-structured interviews were also conducted during this period and still photography offered visual snapshots to accompany written field notes (Davies, 1999).

\section{Interviews and Participants}

For both projects, interviews were conducted on site at the AJM with founding members, established volunteers and newcomers so as to harness a spectrum of experiences. Everyone at the AJM was a volunteer. A total of twenty-six volunteers participated in the interviews, 
comprising eighteen men and eight women. Volunteers requested real names be used in the dissemination of the research as an attributed acknowledgement and record of their contributions to the AJM, and this was in line with approved institutional ethics protocols. Fourteen volunteers were interviewed for Project 1. Project 2 involved repeat interviews with two volunteers who had previously been interviewed in Project 1, and interviews with twelve volunteers who had not been captured in the earlier project. The repeat interviews with volunteers holding key positions in the institution (a former general manager and the collections manager), provided the researcher with an opportunity to report back on initial findings as the research progressed and to undertake respondent validation at the institutional level. The multiple site visits, and particularly the period of participant observation, enabled the stories of the twenty-six interviewees to be contextualised alongside the experiences of the larger cohort of between 50 and 60 volunteers, almost all of whom had no form of paid employment. The majority of volunteers were middle class Anglo-Australians over the age of 65. Many of the volunteers were couples, and though gender parity had not quite been reached, this led to a significant proportion of volunteers being women. In recent years, a larger cohort of female volunteers aged 50 and over has emerged, with their participation largely a result of their need to undertake fifteen hours of volunteering per week in order to receive the government unemployment benefits for older Australians. Two of the women interviewed for this study were from that new group of volunteers.

\section{Data Analysis}

In the case of both projects, the research interviews were recorded and transcribed verbatim. The transcripts from Project 1 were imported into the Project 2 Nvivo 10 project file along with the Project 2 transcripts and other data sources, including field notes, photographs taken during site visits, and archival materials such as AJM newsletters, pamphlets and other ephemera. The combined data set was coded thematically according to the typology of DIY 
heritage institutions put forward by Baker and Huber (2013), which identified three structural functions community archives and museums of popular music serve for their communities of practice - that is, cultural, social and affective functions. The two research projects from which this article emerge did not set out to consider the extent to which the AJM, as a community archive, could be considered a third place, nor the extent to which the practices of the volunteers might constitute serious leisure. However, over time, the data began to point to the importance of the AJM to the social lives and well-being of its volunteers. A moment of "analytic inspiration" occurred, what Gubrium and Holstein (2014, p. 35) describe as a shift in conceptual imagination that can transform the research question and subsequent analysis. Therefore, the data coded to the social and affective dimensions of DIY heritage institutions by Sarah Baker was subsequently re-coded by her according to indicators of third place identified by Oldenburg (1996/7, 1999), and these new codes were audited by Zelmarie Cantillon. The collaborative analysis (Cornish, Gillespie, \& Zittoun, 2014) of the data revealed similarities between community archives and third places, but also important differences. These similarities and differences are highlighted in this article by narrowing our focus to how sociality, friendship, caring, living and productivity are expressed in the AJM.

\section{Results and Discussion}

The AJM is more than just a heritage institution - it is also a space which brings people together and creates a sense of community. While the AJM attracts visitors and volunteers with an interest in jazz music, it also enables more general forms of association by being as accommodating, accessible and welcoming as possible. Housed in an old car mechanics' workshop that was renovated and converted by volunteers (see Sutton, 2015) and sharing its grounds with a nursery (see Figure 1), the AJM is an unpretentious, "low profile" establishment (Oldenburg, 1999). Volunteers work at communal tables and in open-plan offices that are conducive to collaboration and conversation, and the museum features spaces 
dedicated to socialising, including a tearoom and adjacent outdoor patio area where volunteers convene for lunch and tea breaks.

\section{[INSERT FIGURE 1 HERE]}

As a volunteer-run initiative, it is currently open to the public three days per week, as well as being available at various times for group visits featuring live music, food and guided tours of the museum. It should be noted, however, that the AJM is not easily accessible by public transport, being located in the outer suburb of Wantirna in Victoria, 25 kilometres from Melbourne's CBD. As some of the interviewees pointed out, this is the only viable location for the AJM due to the affordable rent offered by Parks Victoria, from whom the building is leased (Baker \& Huber, 2012; Sutton, 2015). That is, the capacity for the AJM to be accommodating and accessible is somewhat restricted by the limited financial, spatial and human resources typical of DIY heritage institutions (Baker, 2017).

Volunteers become involved in the AJM in a number of ways, including hearing about it through friends and acquaintances, on the radio, online and via volunteer agencies. Newcomers are given a volunteer handbook to "assimilate" (Oldenburg, 1996/7) them into the culture, aims and practices of the AJM. Many of the volunteers have a long-standing interest in and knowledge of jazz music, often having been involved in the local jazz scene in the past and into the present (as musicians and as consumers). Volunteers who are jazz enthusiasts bring valuable vernacular knowledge to the practice of preservation (Baker \& Huber, 2012). However, an affiliation with jazz is not a requirement for volunteering, and the AJM also welcomes volunteers without a pre-existing knowledge of the jazz scene or skills directly relevant to heritage and preservation work. These volunteers may live nearby or have heard about the AJM through friends, and come to the institution simply seeking a leisure 
space, a sense of community or a new hobby. They bring to the institution more generic skills such as sound engineering expertise, computer skills and "business acumen" (Ray S.). For these volunteers, their initial experiences of the institution may be more akin to casual leisure rather than serious leisure. However, with long-term involvement in the AJM, all volunteers become more committed to the institution and its preservationist aims, and develop relevant skills on-the-job, whether relating to knowledge of jazz histories, preservation techniques, curatorial practices or museum management (Baker \& Huber, 2012). This kind of "situated learning” (Lave \& Wenger, 1991) is a key characteristic of DIY heritage institutions such as the AJM, and is part of what transforms casual leisure into serious leisure for volunteers.

The AJM may be understood to be inclusive, functioning as a "leveler" (Oldenburg, 1999), since there are no formal restrictions for participation based on factors such as age, gender, occupation, class, ethnicity or skill sets. Nonetheless, the AJM is not an entirely egalitarian space. Hierarchies exist based on one's skills, expertise, cultural capital and the extent to which their practices could be described as "serious" or "casual." Indeed, some participants with limited jazz knowledge reported difficulty "fitting in" when they first started volunteering at the AJM, which was later resolved through the kinds of informal sociality that the institution fosters.

\section{Sociality and Friendship}

One of the things I was struck with when I first came here was the effervescent style of operation ... the people were great to work with, and to meet, and to have a joke and a laugh with. We don't take ourselves too seriously here, we have a lot of fun - as I'm sure you would have evidenced when you first came in this morning, and heard the laughter and camaraderie that existed between the people. (Ray S.) 
The AJM is a space for preservation, curation and education, but as Ray suggested above, also a space for conversation, entertainment and laughter. DIY heritage institutions serve social and affective functions as well as their most obvious cultural functions (Baker, 2017; Baker \& Huber, 2013). As a publicly accessible cultural institution run entirely by volunteers, the AJM provides neutral ground for leisure and informal sociality, and volunteers and visitors alike can choose to go to the museum as little or as often as they desire. What keeps volunteers coming to the museum regularly, then, is not only the important heritage work that they do, but the convivial, warm atmosphere of the place. As one volunteer noted, having fun is part of what makes unpaid labour worth his time - a sentiment common among volunteers in a variety of heritage institutions (see also Graham, 2004; Holmes, 2003).

Even though the AJM is a space for serious work, conversations between volunteers are light-hearted. As one volunteer explained, they try to keep "a maximum of lightness" (Gretel) to the job so that their activities do not come to resemble the stressful working lives from which they have retired. As is typical of a third place, the sociality among volunteers of the AJM is characterised by witty banter. Oldenburg (1999) observed that this kind of humour may appear rude or impolite, but is intended to be playful. Specifically, the volunteers frequently spoke of interactions such as their "politically incorrect" jokes (Gretel) and "blokeish humor" (Ralph). Of course, this kind of affectionate teasing - a key component of the social world of the AJM - may also work to exclude certain cohorts of potential volunteers, including ethnic minorities, LGBTIQ and younger people.

For the current cohort of volunteers, however, the cheerful nature of the AJM has considerable benefits to their well-being. The collections manager, Mel, commented that, since many volunteers are in poor health, going to the museum can act as a "tonic" - what Oldenburg (1999) specifically calls a "spiritual tonic" (p. 58) - to make them feel happier and more satisfied with their everyday lives. In this way, the AJM, as a third place, "contributes 
to a healthy perspective by combining pleasure with association in a wide group" (Oldenburg 1999, p. 50). Thus, the volunteers, or "regulars," are not drawn to this third place only for its particular heritage functions or for their love of jazz, but also for its sociality and the personal benefits volunteers can reap from their participation within it.

Another such benefit is that the welcoming, convivial sociality characteristic of third places like the AJM supports the formation of friendships. Volunteers often mentioned that the friendly atmosphere, and the people who create it, are what make the museum special. In Figure 2, we catch a glimpse of this atmosphere through the joy written on Irene's face. Having just set up the Ray Marginson Library in readiness for a lunchtime concert for a tour group, Mavis and Irene pose for the researcher's camera. Mavis then went on to explain that creating connections and forming bonds is one of the most rewarding aspects of her role hosting museum visitors and running tours allows plenty of opportunities to meet new people, and her fellow volunteers are "a lovely, wonderful group to work with, and you get such a lot of benefit from it". When asked what keeps them coming back to the AJM, Mavis, Irene and numerous other volunteers stressed the significance of friendship.

[INSERT FIGURE 2 HERE]

Importantly, the voluntary nature of one's engagements with the AJM cultivates what Oldenburg (1996/7, 1999) calls “neutral ground." In other words, those who work in the AJM are not obliged to be there, but choose to be because of the positive experiences it offers. In addition to friendship and conviviality, another beneficial experience is that of novelty, with different tasks to work on each day and unexpected interactions with visitors and other volunteers. In this way, the AJM fosters association in general forms - such as one-off engagements with visitors - and more intimate forms - such as close friendships between 
long-standing volunteers. As Oldenburg (1999) observed, in a third place, there is "no dependence upon any particular friend" (p. 64), but rather a collective sense of friendship, or "friends by the set" (p. 63). With up to sixty volunteers present at the AJM at any one time, a multiplicity of friendships can proliferate, and this means volunteers can participate in the museum at any given time and have fun, friendly interactions with others. This is, in part, what contributes to a particular social world with "an atmosphere of acceptance and belonging" (Oldenburg, 1996/7, p. 9). Much like a traditional workplace, there is "some objective purpose" (Oldenburg, 1999, p. 24) to participation in the museum, but this purpose - the preservation of Australian jazz music's material past - is what brings people together; it is what lays the groundwork for association and friendship, even for those volunteers without an inherent love of jazz.

\title{
Caring, Living and Productivity
}

\begin{abstract}
Mel takes an interest in everybody's welfare ... I would be lost without the archive because I live alone with a cat and a lot of us depend on Mel, because not only is he collections manager, but he looks after everybody's health and welfare. (Gretel)
\end{abstract}

The warm sociality and opportunities for forging friendships are part of what makes third places particularly important for the well-being of retired and elderly people. As a third place, the AJM provides retirees "the means for keeping in touch with others and continuing to enjoy the life of the community" (Oldenburg, 1996/7, p. 9). Rosenbaum et al. (2007) noted six common life experiences among older adults which may erode their social networks: retirement, divorce, separation, "empty nest” syndrome, chronic illness, and bereavement. Campbell (2014) and Rosenbaum et al. (2007) observed that participation in third places may remedy the negative effects of such experiences, while Greenfield and Marks (2004) 
identified that volunteering similarly operates as a protective factor for the well-being of older adults undergoing these role-identity changes. Volunteers of the AJM spoke of the importance of this DIY institution for fostering the well-being of members who lived alone, had fallen ill or lost loved ones. For example, participants mentioned the importance of the AJM in providing those volunteers who had been widowed with "a reason for them to get out of bed" (Mel). One volunteer, Bill, explained that he started volunteering shortly after his wife died of cancer, and expressed that the AJM had been "very therapeutic" in that regard.

Although not a space for the formalised delivery of "therapeutic recreation" (see Carruthers \& Hood, 2007; Wilhite, Keller, \& Caldwell, 1999), the AJM nonetheless operates as a kind of surrogate caregiver, offering (serious) leisure activities with therapeutic benefits for older adults. As observed by Glover and Parry (2009), third places may be understood as “therapeutic landscapes” (see also Finlay et al., 2015; Milligan, Gatrell, \& Bingley, 2004). The social world of the AJM is therapeutic in that it assists participants in coping with and transcending difficult life experiences (death, divorce and chronic illness), as well as helping to prevent other negative effects (loneliness, isolation and related mental health issues) (Caldwell, 2005). As Caldwell (2005) explained, these therapeutic functions are tied to a number of "leisure-related protective factors" (p. 17), including engagement in meaningful or interesting activity, possibilities for social support and friendship, opportunities to demonstrate self-efficacy, and experiences of fun, relaxation and distraction. The literature on volunteering and well-being among older adults has similarly noted the importance of factors like social support to enhancing life satisfaction and benefiting psychological and physical health (Pilkington et al., 2012; Schwingel et al., 2009; Tang et al., 2010; Thoits \& Hewitt, 2001). Many of these protective factors are present in the social world of the AJM, as discussed above and in more depth below. 
With each of the major life events noted by Rosenbaum et al. (2007), the spheres of "work" and "home" begin to function less effectively as social support mechanisms. That is, older individuals experience a decrease in social capital with the loss of everyday interaction with work friends, partners and children, or with the loss of mobility and personal freedom associated with serious illnesses. Thus, engagement in third places becomes more important than ever. These sites act as "informal support groups" (see Litwak, 1985), providing "not only emotional support but practical assistance as well” (Oldenburg, 2003, p. 1375). As spaces for talking, laughing, caring and offering companionship, third places can have positive impacts on the mental health of regulars, curbing feelings of isolation and loneliness and improving quality of life (Campbell, 2014; Cheang, 2002; Rosenbaum, et al. 2007, 2009). In the case of the AJM, the act of volunteering as serious leisure can restore similar kinds of social networks typically associated with workplaces, but in a more informal setting. Even for those engaging in more casual forms of leisure, the AJM provides ample opportunities to forge social connections through shared experiences.

Perhaps quite unlike a traditional workplace, the AJM possesses home-like qualities. This is less to do with the design of the space, and more to do with the sociality and friendships that cultivate a particular atmosphere - as one interviewee put it, "I think we feel like it's a family" (Gretel). This sense of community is formed through the ways in which the volunteers care for each other collectively: "We look after one another" (Peter). For instance, volunteers Jim and Mel spoke of how they had been assisting another long-time volunteer, Ric, who has been struggling with a serious illness. Although Ric was once the AJM's collections manager, he is no longer able to undertake many archival tasks on his own. Nonetheless, Ric continues to participate in the AJM "as part of his social therapy" (Mel). In Figure 3, Jim can be observed sitting with Ric, assisting him in the preservation of photographs to archival standard. 
[INSERT FIGURE 3 HERE]

The interviewees brought attention to the importance of Mel, who at the time of the interviews was the AJM's collections manager, in fostering such a caring environment. Ralph, for example, talked about Mel as being "a particularly caring person" and this results in him being "a strong driver of the climate" of the AJM. For Mel, caring for the people of the AJM was just as important as caring for the artefacts in its collection: "the social aspects of volunteering are probably just as important as what you're actually doing. In some cases, they might be even more so". As Gretel stated, Mel "looks after everybody's health and welfare", and this extends beyond the physical space of the AJM as well. For instance, after one volunteer, Eric, was injured in a fall, Mel took it upon himself to monitor Eric's recovery, even driving him to and from his physiotherapy and hospital appointments. As evidenced by the treatment of Ric and Eric, the AJM is an accommodating, inclusive and caring space for the members of its community with illnesses and disabilities.

Moreover, the AJM is not only beneficial to its volunteers in terms of providing support networks, building friendships and creating community, but also for how it enables a productive, "meaningful retirement" $(\mathrm{Mel})$, allowing them to contribute to the preservation of popular music heritage. As outlined by Tang et al. (2010), participating in meaningful activity has a positive influence on the mental health of older adults. Volunteers in the AJM expressed that working in the museum is akin to a hobby or passion, helping them to keep busy and giving them a sense of purpose after retirement. In particular, Ken pointed out how this kind of activity comes with "a great feeling of satisfaction" compared to hobbies carried out at home, because the work is undertaken collectively and recognised by fellow volunteers and visitors to the museum. 
A number of the volunteers emphasised the importance of their work at the archive in maintaining an "active brain" (Maria). The majority of volunteers come to the AJM with no background in archiving, and many have no background with jazz. Thus, work at the AJM involves situated learning of new skills relating to archiving, preservation, curation and display (see also Orr 2006; Stebbins 1982, 1996), and also in regard to accumulating historical knowledge of Australia's jazz scenes through these practices. Studies have shown that this kind of ongoing, informal learning has positive effects on mental and emotional well-being for older adults (Åberg, 2016; Jenkins \& Mostafa, 2015). In Maria’s terms, the volunteer work is "keeping you young". Further, Merriam and Kee (2014) found that lifelong learning has positive impacts on the well-being of the wider community as well. Learning assists older adults in remaining active, healthy and engaged in social life, thereby reducing pressure on family and community resources (Merriam \& Kee, 2014). Additionally, the community also benefits from the valuable contributions older adults make when sharing or putting to use their acquired skills and knowledge (Merriam \& Kee, 2014).

Clearly, the AJM functions as a third place in that it cares not only for the artefacts it preserves, but for ageing members of the local community. This also reflects the "serious" nature of much of the leisure taking place, which Stebbins stresses is characterised by “earnestness, sincerity, importance, and carefulness, rather than gravity, solemnity, joylessness, distress, and anxiety" (p. 258). The volunteers help each other out with tasks such as archiving and curation, as well as aspects of day-to-day living, acting as "natural support groups or 'mutual aid' societies” (Oldenburg, 1996/7, p. 8). This creates a comforting, home-like atmosphere, which has been sustained by prominent people in the institution who look out for the well-being of others, described by Oldenburg (1996/7, p. 8) (citing Jane Jacobs) as the "public characters" of a particular milieu. 
By fostering the AJM as a caring environment, it becomes, for the volunteers, a place for living: an affective, social institution whereby practices inspired by an engagement with jazz heritage have unexpected and positive outcomes - for those with and without a love for the music being collected. Volunteering in a DIY heritage institution like the AJM also provides an opportunity for a meaningful retirement by way of the contributions that can be made to the preservation of jazz music's material past: these volunteers understand their work to be of value to the institution, but they also recognise the value the institution provides to them in the sense of the supportive community it fosters.

\section{Conclusion}

As our discussion has demonstrated, the AJM exhibits both resonances with and departures from Oldenburg's conceptualisation of third place. Most obviously, the AJM can be understood as a third place in terms of its social and affective functions. It is at once a heritage institution for preservation, education, working and productivity, and a fun, vibrant space for leisure, socialising, laughing, caring and living. A sense of community is present in that volunteers feel they belong and matter to the group (both in terms of friendship and in contributing to archival tasks), and that they develop affective bonds - "a shared emotional connection” (McMillan \& Chavis, 1986, p. 9) - based on their activities and social interactions. Further, the AJM is a caring environment, benefiting the individuals who engage with it - by meeting the needs necessary to support the mental, emotional, physical and social well-being of volunteers - and the wider community - by preserving localised popular music heritage, and by supporting the social lives and health of ageing adults.

Nevertheless, as a site where serious leisure is frequently enacted, the AJM blurs the distinctions between home, work and community spaces put forth by Oldenburg. Although clearly operating as a community space (with voluntary participation and a distinctly warm, informal atmosphere), the AJM also shares work- and home-like qualities. Moreover, the 
extent to which it can be considered an egalitarian, welcoming space is somewhat limited. Indeed, although there are no formal restrictions on who can visit and volunteer, the social world and physical location of the AJM can have exclusionary effects. These departures from Oldenburg's understanding of third place, however, do not exempt sites such as the AJM from being considered third places, since they still operate as spaces for community and voluntary, informal sociality. Rather, such points of difference expand on Oldenburg's work, reframing our understandings of informal gathering places so as to acknowledge the complexity, heterogeneity and uneven power dynamics that characterise all social spaces.

Our case study is, of course, limited in that it relates to one DIY heritage institution, which specifically collects Australian jazz artefacts and is physically situated in an outer suburb of Melbourne. However, the key themes we discuss emerge from an international comparative data set, and thus our findings have wider applicability to other heritage institutions. Future research could expand the scope of this article by considering its key thematics in relation to mainstream, officially authorised heritage institutions, institutions focused on other (sub)cultural activities, and institutions in different locations across the globe. Such studies may also benefit from different methodologies, such as undertaking a comparative, multi-sited approach or by using an autoethnographic approach based on one's own experiences as a volunteer. Further, there is also value in exploring how online DIY archives and museums may function as digital third places.

Despite the narrow focus of this article, our findings nonetheless relate to other DIY heritage institutions, given the way that the AJM's characteristics are shared by many other community archives and museums (Baker, 2017). One such shared characteristic is that the ongoing involvement of volunteers in the community heritage sector is motivated not only by the important work of preservation, curation and display that they do, but by the social and affective benefits that go along with it. Indeed, to ensure a committed and passionate 
volunteer workforce, there is considerable value in community archives and museums actively implementing strategies that support a heritage institution's use as a third place. For example, efforts should be made to cultivate collaborative work spaces, and time should be set aside for informal social activity throughout the day, such as by sharing food and drinks during breaks. Establishing such practices will enable other qualities of third place to develop organically - that is, friendships will form and strengthen, and volunteers will subsequently come to care for one another and operate as an informal support group. In terms of enhancing the well-being of retirees, our findings highlighted positive feelings associated with the novelty, productivity and learning that underpin work in the AJM. Thus, other DIY heritage institutions should ensure that volunteers are taught varied skills and knowledge "on the job," rather than being restricted to set roles and responsibilities based on their existing skills. As a final recommendation, since our findings showed that egalitarianism in the AJM was lacking in some ways and more prominent in others, it would be beneficial for DIY heritage institutions to develop more specific policies aimed at inclusivity. For instance, being inclusive of volunteers (and prospective volunteers) with disabilities or limited mobility who may need additional assistance from other workers, or help with transport to and from the institution - will have positive impacts on the emotional well-being of these people, as well as further cultivating a caring, supportive social world within the institution.

By creating opportunities for volunteers and visitors to chat, laugh and help each other out, DIY heritage institutions can serve vital roles in the lives of individual volunteers and in the broader community. In these institutions, the benefits of serious leisure extend far beyond cultural and heritage dimensions, working to enhance the overall well-being of those who engage with them. 


\section{References}

Aabø, S., \& Audunson, R. (2012). Use of library space and the library as place. Library \& Information Science Research, 34(2), 138-149. doi:10.1016/j.lisr.2011.06.002.

Åberg, P. (2016). Nonformal learning and well-being among older adults: Links between participation in Swedish study circles, feelings of well-being and social aspects of learning. Educational Gerontology, 42(6), 411-422. doi:10.1080/03601277.2016.1139972

Baker, S. (2017). Community custodians of popular music's past: A DIY approach to heritage. London: Routledge.

Baker, S., \& Huber, A. (2012). "Masters of our own destiny": Cultures of preservation at the Victorian Jazz Archive in Melbourne, Australia. Popular Music History, 7(3), 263282. doi: 10.1558/pomh.v7i3.263.

Baker, S., \& Huber, A. (2013). Notes towards a typology of the DIY institution: Identifying do-it-yourself places of popular music preservation. European Journal of Cultural Studies, 16(5), 513-530. doi:10.1177/1367549413491721.

Banning, J.H., Clemons, S., McKelfresh, D., \& Gibbs, R.W. (2010). Special places for students: Third place and restorative place. College Student Journal, 44(4), 906-912.

Caldwell, L.L. (2005). Leisure and health: Why is leisure therapeutic? British Journal of Guidance \& Counselling, 33(1), 7-26. doi:10.1080/03069880412331335939

Campbell, N.M. (2014). Designing retirement community third places: Attributes impacting how well social spaces are liked and used. Journal of Interior Design, 39(4), 1-14. doi:10.1111/joid.12035.

Carruthers, C., \& Hood, C.D. (2007). Building a life of meaning through Therapeutic Recreation: The Leisure and Well-Being Model, part I. Therapeutic Recreation Journal, 41(4), 276-297. 
Cheang, M. (2002). Older adults' frequent visits to a fast-food restaurant: Nonobligatory social interaction and the significance of play in a "third place." Journal of Aging Studies, 16(3), 303-321. doi:10.1016/S0890-4065(02)00052-X.

Cornish, F., Gillespie, A., \& Zittoun, T. (2014). Collaborative analysis of qualitative data. In U. Flick (Ed.), The SAGE handbook of qualitative data analysis (pp. 79-93). London: SAGE Publications.

Davies, C.A. (1999). Reflexive ethnography: A guide to researching selves and others. London: Routledge.

Ducheneaut, N., Moore, R.J., \& Nickell, E. (2007). Virtual "third places": A case study of sociability in massively multiplayer games. Computer Supported Cooperative Work, 16(1), 129-166. doi:10.1007/s10606-007-9041-8.

Edwards, D., \& Graham, M. (2006). Museum volunteers: A discussion of challenges facing managers in the cultural and heritage sectors. Australian Journal of Volunteering, 11(1), 19-27. doi:10.1007/s10606-007-9041-8.

Feagin, J.R., Orum, A.M., \& Sjoberg, G. (Eds.) (1991). A case for the case study. Chapel Hill: University of North Carolina Press.

Finlay, J., Franke, T., McKay, H., \& Sims-Gould, J. (2015). Therapeutic landscapes and wellbeing in later life: Impacts of blue and green spaces for older adults. Health \& Place, 34, 97-106.

Fisher, K.E., Saxton, M.L., Edwards, P.M., \& Mai, J.-E. (2007). Seattle Public Library as place: Reconceptualizing space, community, and information at the Central Library. In J. Buschman \& G.J. Leckie (Eds.), The library as place: History, community, and culture (pp. 135-160). Westport, CT: Libraries Unlimited. 
Flinn, A., Stevens, M., \& Shepherd, E. 2009. Whose memories, whose archives? Independent community archives, autonomy and the mainstream. Archival Science, 9(1/2), 71-86. doi:10.1007/s10502-009-9105-2.

Freeman, J. (2008). Great, good, and divided: The politics of public space in Rio de Janeiro. Journal of Urban Affairs, 30(5), 529-556. doi:10.1111/j.1467-9906.2008.00417.x.

Glover, T.D., \& Parry, D.C. (2009). A third place in the everyday lives of people living with cancer: Functions of Gilda's Club of Greater Toronto. Health and Place, 15(1), 97106. doi:10.1016/j.healthplace.2008.02.007.

Graham, M. (2004). Volunteering as heritage/volunteering in heritage. In R.A. Stebbins \& M. Graham (Eds.), Volunteering as leisure/leisure as volunteering: An international assessment (pp. 13-30). Cambridge, MA: CABI Publishing.

Greenfield, E.A., \& Marks, N.F. (2004). Formal volunteering as a protective factor for older adults' psychological well-being. Journal of Gerontology, 59B(5), S258-S264. doi:10.1093/geronb/59.5.S258.

Gubrium, J.F., \& Holstein, J.A. (2014). Analytic inspiration in ethnographic fieldwork. In U. Flick (Ed.), The SAGE handbook of qualitative data analysis (pp. 35-48). London: SAGE Publications.

Harris, C. (2007). Libraries with lattes: The new third place. Australasian Public Libraries and Information Services, 20(4), 145-152.

Hindley, D. (2018). "More than just a run in the park": An exploration of Parkrun as a shared leisure space. Leisure Sciences. doi:10.1080/01490400.2017.1410741.

Holmes, K. (2003). Volunteers in the heritage sector: A neglected audience? International Journal of Heritage Studies, 9(4), 341-355. doi:10.1080/1352725022000155072. Jenkins, A., \& Mostafa, T. (2015). The effects of learning on wellbeing for older adults in England. Ageing \& Society, 35(10), 2053-2070. doi:10.1017/S0144686X14000762. 
Lave, J., \& Wenger, E. (1991). Situated learning. Cambridge: Cambridge University Press.

Lin, H., Pang, N., \& Luyt, B. (2015). Is the library a third place for young people? Journal of Librarianship and Information Services, 47(2), 145-155. doi:10.1177/0961000614532303.

Litwak, E. (1985). Complementary roles for formal and informal support groups: A study of nursing homes and mortality rates. Journal of Applied Behavioural Science, 21(4), $407-425$.

Mair, H. (2009). Club life: Third place and shared leisure in rural Canada. Leisure Sciences, 31(5), 450-465. doi:10.1080/01490400903199740.

McArthur, J.A., \& White, A.F. (2016). Twitter chats as third places: Conceptualizing a digital gathering site. Social Media + Society, 2(3), 1-9. doi:10.1177/2056305116665857.

McMillan, D.W., \& Chavis, D.M. (1986). Sense of community: A definition and theory. Journal of Community Psychology, 14(1), 6-23.

Mehta, V., \& Bosson, J.K. (2010). Third places and the social life of streets. Environment and Behavior, 42(6), 779-805. doi:10.1177/0013916509344677.

Merriam, S.B., \& Kee, Y. (2014). Promoting community wellbeing: The case for lifelong learning for older adults. Adult Education Quarterly, 64(2), 128-144. doi: $10.1177 / 0741713613513633$.

Milligan, C., Gatrell, A., \& Bingley, A. (2004). 'Cultivating health': Therapeutic landscapes and older people in northern England. Social Science \& Medicine, 58(9), 1781-1793. doi:10.1016/S0277-9536(03)00397-6

Moore, R.J., Hankinson Gathman, E.C., \& Ducheneaut, N. (2009). From 3D space to third place: The social life of small virtual spaces. Human Organization, 68(2), 230-240. doi:10.17730/humo.68.2.q673k16185u68v15. 
Morrow-Howell, N. (2010). Volunteering in later life: Research frontiers. The Journals of Gerontology: Series B, 65B(4), 461-469. doi:10.1093/geronb/gbq024.

Musick, M.A., Herzog, A.R., \& House, J.S. (1999). Volunteering and mortality among older adults: Findings from a national sample. Journal of Gerontology: SOCIAL SCIENCES, 54B(3), S173-S180.

Oldenburg, R. (1996/7). Our vanishing “third places.” Planning Commissioners Journal, 25, $6-10$.

Oldenburg, R. (1999). The great good place: Cafes, coffee shops, bookstores, bars, hair salons, and other hangouts at the heart of a community. New York: Marlowe \& Company.

Oldenburg, R. (2003). Third places. In K. Christensen \& D. Levinson (Eds.), Encyclopedia of community (pp. 1373-1376). Thousand Oaks, CA: SAGE Publications.

Oldenburg, R., \& Brissett, D. (1982). The third place. Qualitative Sociology, 5(4), 265-284. doi:10.1007/BF00986754.

Orr, N. (2006). Museum volunteering: Heritage as “serious leisure.” International Journal of Heritage Studies, 12(2), 194-210. doi:10.1080/13527250500496169.

Pilkington, P.D., Windsor, T.D., \& Crisp, D.A. (2012). Volunteering and subjective wellbeing in midlife and older adults: The role of supportive social networks. The Journals of Gerontology: Series B, 67(2), 249-260. doi:10.1093/geronb/gbr154.

Purnell, D. (2015). Expanding Oldenburg: Homes as third places. Journal of Place Management and Development, 8(1), 51-62. doi:10.1108/JPMD-03-2014-0006.

Putnam, R.D. (2000). Bowling alone: The collapse and revival of American community. New York: Simon \& Schuster. 
Ragin, C.C., \& Schneider, G.A. (2014). Case-oriented theory building and theory testing. In M. Williams \& W.P. Vogt (Eds.), The SAGE handbook of innovation in social research methods (pp. 150-166). London: SAGE Publications.

Rosenbaum, M.S. (2006). Exploring the social supportive role of third places in consumers' lives. Journal of Service Research, 9(1), 59-72. doi:10.1177/1094670506289530.

Rosenbaum, M.S., Ward, J., Walker, B.A., \& Ostrom, A.L. (2007). A cup of coffee with a dash of love: An investigation of commercial social support and third-place attachment. Journal of Service Research, 10(1), 43-59. doi:10.1177/1094670507303011.

Rosenbaum, M.S., Sweeney, J.C., \& Windhorst, C. (2009). The restorative qualities of an activity-based, third place café for seniors: Restoration, social support, and place attachment at Mather's-More Than a Café. Seniors Housing \& Care Journal, 17(1), $39-54$

Schwingel A., Niti, M.M., Tang, C., \& Ng, T.P. (2009). Continued work employment and volunteerism and mental well-being of older adults: Singapore longitudinal ageing studies. Age and Ageing, 38(5), 531-537. doi:10.1093/ageing/afp089.

Simmel, G. (1949). The sociology of sociability (E.C. Hughes, Trans.). American Journal of Sociology, 55(3), 254-261. doi:10.1086/220534.

Slater, A., \& Koo, H.J. (2010). A new type of "third place"? Journal of Place Management and Development, 3(2), 99-112. doi:10.1108/17538331011062658.

Stamer, D., Lerdall, K., \& Guo, C. (2008). Managing heritage volunteers: An exploratory study of volunteer programmes in art museums worldwide. Journal of Heritage Tourism, 3(3), 203-214. doi:10.1080/17438730802138949.

Stebbins, R.A. (1982). Serious leisure: A conceptual statement. The Pacific Sociological Review, 25(2), 251-272. 
Stebbins, R.A. (1996). Volunteering: A serious leisure perspective. Nonprofit and Voluntary Sector Quarterly, 25(2), 211-224. doi:10.1177/0899764096252005.

Stebbins, R.A. (1997). Casual leisure: A conceptual statement. Leisure Studies, 16(1), 17-25. doi:10.1080/026143697375485.

Sutton, R. (2015). The Australian Jazz Museum: All that Aussie jazz - a potted history of the Victorian Jazz Archive, 1996-2014. In S. Baker (Ed.), Preserving popular music heritage: Do-it-yourself, do-it-together (pp. 196-206). New York: Routledge.

Tang, F., Choi, E., \& Morrow-Howell, N. (2010). Organizational support and volunteering benefits for older adults. The Gerontologist, 50(5), 603-612. doi:10.1093/geront/gnq020.

Thoits, P.A., \& Hewitt, L.N. (2001). Volunteer work and well-being. Journal of Health and Social Behavior, 42(2), 115-131.

Van Willigen, M. (2000). Differential benefits of volunteering across the life course. Journal of Gerontology: SOCIAL SCIENCES, 55B(5), S308-S318.

Wilhite, B., Keller, M.J., \& Caldwell, L. (1999). Optimizing lifelong health and wellbeing: A health enhancing model of therapeutic recreation. Therapeutic Recreation Journal, $33(2), 98-108$.

Yang, J. (2015). The art and culture companions: Art museum volunteering as serious leisure in Finland. International Journal of the Inclusive Museum, 7(3/4), 9-20.

Yuen, F., \& Johnson, A.M. (2017). Leisure spaces, community, and third places. Leisure Sciences, 39(3), 295-303. doi:10.1080/01490400.2016.1165638. 